the evidence limit the quality of patients' care. Some evidence is simply lacking-for example, on the aetiology of upper respiratory tract infections, and on the reasons for variation in health seeking behaviours between people who have the same symptoms. Even when there is relevant evidence, it is not always implemented. ${ }^{4}$

For evidence to be implemented in primary care it must be accessible as well as relevant. ${ }^{5}$ The sheer volume of published studies documenting medical and clinical research means it is impossible for busy clinicians to read, let alone digest, sufficient material to keep up to date. Clinical guidelines can provide clinicians with concise, evidence based recommendations to enable the delivery of high quality and well researched care for their patients. ${ }^{6}$ However, the guidelines must be regularly updated, ${ }^{5}$ and they should evaluate the methodological rigour of included studies and be clear about both the application and the limitations of the recommendations.?

With good clinical guidelines, clinicians can confidently use research evidence as a basis for their individualised decision making with patients, while also considering patients' personal histories and preferences. Mant and colleagues indicate that these criteria are not met by the UK clinical guidelines for stroke, thus undermining the applicability of the recommendations. ${ }^{2}$

The PROGRESS trial not only had a different patient profile than that seen in primary care but yielded results that are open to interpretation. In particular, the cause of the substantial reduction in stroke risk seen in the trial (relative risk reduction 43\%, $95 \%$ confidence interval 30 to 54 ) is unclear: is it due to the use of a thiazide diuretic and angiotensin coverting enzyme inhibitor in combination or alone, or simply due to the lowered blood pressure $?^{8}$ Really useful guidelines would help clinicians to interpret these findings, rather than just uncritically basing clinical recommendations on them.

Evidence from randomised controlled trials is only a portion of the real knowledge that is needed in primary care. Such trials provide vital information about the effectiveness of interventions in selected populations of patients. However, general practitioners require evidence about how an individual patient will respond to an intervention. Active involvement of patients in decisions about their health care can improve health outcomes. For instance, patients with breast cancer have less anxiety and depression if treated by doctors who involve them in the decision making, and patients with diabetes achieve better blood sugar control if involved in discussions about their management. ${ }^{9}$

Mant and colleagues call for further research in the primary care population to determine the efficacy and appropriateness for individual patients of intensive lowering of blood pressure. ${ }^{2}$ Their call is well justified and should be heeded.

Sharon Mickan senior research fellow in general practice (Sharon.Mickan@gmail.com)

Deborah Askew postdoctoral research fellow, School of Medicine

University of Queensland, Brisbane, QLD 4072, Australia

Competing interests: None declared.

1 PROGRESS Collaborative Group. Randomised trial of a perindoprilbased blood pressure lowering regimen among 6,105 individuals with a based blood pr previous stroke or tr

2 Mant J, McManus R, Hare R. Applicability to primary care of national clinical guidelines on blood pressure lowering for people with stroke: cross sectional study. BMJ 2006;332:635-7.

3 Van Weel C. International research and the discipline of family medicine. EurJ Gen Pract 1999;5:2-7.

4 NHS. R\&D strategic review-primary care. Report of topic working group, June 1999. www.dh.gov.uk/assetRoot/04/06/89/53/04068953. pdf (accessed 8 Mar 2006).

5 Moulding N, Fahy N, Foong LH, Yeoh J, Silagy C, Weller D. A systematic review of the current status of evidence-based medicine and its potential application to Australian general practice. A report to the Commonwealth Department of Health and Family Services. Adelaide: Department wealth Department of Health and Family Services. Adelaide: Depar
of General Practice, Flinders University of South Australia, 1997.

6 of General Practice, Flinders University of South Australia, 1997. al. Validity of the Agency for Healthcare Research and Quality clinical practice guidelines: how quickly do guidelines become outdated? JAMA 2001;286:1461-7.

7 Watine J, Friedberg B, Nagy E, Onody R, Oosterhuis W, Bunting PS, et al. Conflict between guideline methodologic quality and recommendation validity: a potential problem for practitioners. Clin Chem 2006;52:65-79.

8 Rodgers H.The PROCRESS trial three years later: all aspects of secondRodgers H. The PROGRESS trial three years later: all aspects of second ary prevention after stroke need to be improved. BMJ 2004;329:1404-5. Coulter A, Entwistle V, Gilbert D. Sharing decisions with patients: is the
information good enough? BMJ 1999;318:318-22.

\title{
Grieving the death of a child
}

\section{Health professionals need to be particularly sensitive to the needs of parents}

$\mathrm{T}$ The death of a child brings profound distress and intense grief to the family, challenging all those involved in caring for the family through such times. That such grief can lead to suicide is known, but two cases in this week's BMJ show a particular hazard after a child has died at home: in both cases mothers committed suicide with drugs prescribed for the palliative care of their children (p 647). ${ }^{1}$

There is substantial evidence from comparative and longitudinal studies that the grief of parents following the loss of a child is more intense and prolonged than that of other losses. ${ }^{23}$ Parental vulnerability includes a heightened risk of suicide, especially in the first month, as shown in a nested case-control study of Danish longitudinal registers. ${ }^{4}$ Population based follow-up studies also show that anxiety and depression may last four to nine years after the loss of a child from cancer. ${ }^{5}$

When a child dies suddenly-for instance, through suicide, homicide, violence, or accidental deathparental grief may become complicated by posttraumatic stress reactions arising from the nature of these circumstances, so that the parent has to deal with the interplay of both trauma and grief. ${ }^{6}$

The challenges that arise when a death is prolonged are different. Caring for a child with chronic fatal disease such as cancer may involve intense and prolonged treatments; the sustaining of hope; the denial of the potential for death as the parent fights for the child's survival in a protracted battle with the disease. Anticipatory grieving as the probability of death becomes more real may lead parents to feel guilt about giving in to such a
Practice $\mathrm{p} 647$

BMJ 2006;332:620-1 
possibility-as though they are somehow abandoning the child. Alternatively, their relief that there will be an end to this suffering is ambivalent, again because it means admitting the reality of death.

The parent-usually the mother-may invest her own life so intensely, that she hopes by this to keep the child alive, by force of will, if all else fails. There are also the questions, the blame, and the guilt. Why did this child become ill, in this way? The "if only" "something" had been done differently, or not done. Parents search for information, gathering their own statistics, from which they may find further sources of hope, or alternatively sources of guilt and blame. This intense involvement may lead to an almost symbiotic relationship between mother and dying child in such circumstances, reflecting the desperation, the wish to bring the child back from the brink, and, more deeply in some circumstances, the mother's inner belief that she cannot live if her child dies.

In addition there may be "secrets": that the possibility and then the reality of such a death cannot be spoken of, for fear it will make it happen. This may make for difficulties for the child, who is often well aware of what is happening but who may feel he or she cannot let go for fear the parent will not be able to cope. It may also prevent the goodbyes, the "good death" even in circumstances when death should not be happening, when there is the need for a more positive palliative care.

All these issues may need to be considered in assessing the parent's and family's and child's needs through the period of preparation for the realities of the death and its aftermath. Clinical issues include recognising the dying child's understanding of death and needs at different stages of development; communicating the bad news to the family in a compassionate and supportive way, with later follow-up; having an honest, continuing dialogue that both promotes realistic hope and acknowledges possibilities and probabilities of dying; and ensuring good symptom management for the child. ${ }^{8}$

Looking after the caregiver, both before, during, and in the aftermath of the death is an integral part of comprehensive care. While many paediatric oncology units provide bereavement support for families, there is no strong evidence to inform such care. ${ }^{9}$ Surveys suggest that the quality of care received is generally perceived to be high, ${ }^{10}$ but there is a need for controlled trials in this ethically sensitive field. ${ }^{11}$ Linking to support groups is also of value, for instance Compassionate Friends (www.tcf.org.uk). Support from others who have survived such an experience can help parents to make some meaning of the unthinkable prospect of their child's death and to bring to bear their social, psychological, personal, and spiritual resources to deal with their grief, and to treasure the memories of their child.

Beverley Raphael professor of population mental health and disasters

(b.raphael@uws.edu.au)

University of Western Sydney, Parramatta, Penrith South DC, NSW 1797, Australia

Competing interests: None declared.

1 Davies DE. Parental suicide after the expected death of a child at home. BMJ 2006;332:647-8

2 Sanders CM. A comparison of adult bereavement in the death of a spouse, child and parent. Omega:J Death Dying 1980;10:303-22.

Middleton WP, Raphael B, Martinek N. The bereavement response: A cluster analysis. Br J Psychiatry 1996;169:167-9.

Qin P. Mortensen P. The impact of parental status on the risk of completed suicide Arch Gen Psychiatry Aug 2003;60:797-802.

5 Kreicbergs U, Valdimarsdottir U, Onelov E, Henter J, Steineck G. Anxiety and depression in parents 4-9 years after the loss of a child owing to a malignancy: a population-based follow-up. Psychol Med 2004:34:1431-41.

6 Raphael B, Wooding S. Early mental health interventions for traumatic loss in adults. In: Litz B, ed. Early intervention for trauma and traumatic loss. New York: Guilford Press, 2004.

Kellehear A. Health promoting palliative care Melbourne: Oxford University Press, 1999

Hurwiz CA, Duncan J, Wolfe J Caring for the child with cancer at the close of life. JAMA 2004;292:2141.

9 deCinque N, Monterosso L, Dadd G, Sidhu R, Lucas R. Bereavement support for families following the death of a child from cancer: practice characteristics of Australian and New Zealand paediatric oncology units $J$ Paed Child Health 2004;40:131-5.

10 Seecharan GA, Andresen E, Norris K, Toce S. Parents' assessment of quality of care and grief following a child's death. Arch Ped Adol Med 2004:158:515-20.

11 Kempson DA. Effects of intentional touch on complicated grief of bereaved mothers. Omega:J Death Dying 2000:42:341-53.

\section{Standards for infant formula milk}

\section{Commercial interests may be the strongest driver of what goes into formula milk}

$\mathrm{T}$ The quality of infant feeding is of paramount importance for growth, development, and long term health well into adulthood. ${ }^{1}$ Breast feeding is recognised as the ideal form of infant feeding, providing multiple benefits for child health. ${ }^{2}$ Thus breast feeding should be actively promoted, protected, and supported. Infants who cannot be fed at the breast, who should not receive breast milk, or for whom breast milk is not available need infant formula milks of high quality. ${ }^{3}$

The Codex Alimentarius Commission, part of both the Food and Agriculture Organization of the United Nations (FAO) and the World Health Organization, develops standards, guidelines, and related texts on food to protect consumers' health and to ensure fair trade the more than 160 countries that are members of the Codex Alimentarius. Its standard on infant formula was adopted in 1981, based on scientific knowledge of the $1970 \mathrm{~s}^{4}$ and it is currently being revised.

At the end of November 2005 the Codex Committee on Nutrition and Foods for Special Dietary Uses met in Bonn, Germany, and discussed among other issues revision of the standard on infant formula. The meeting was attended by government delegations of some 71 member states of the committee, along with observers of 32 international non-governmental organisations, mostly umbrella organisations for food manufacturers and other groups with commercial interests in infant formula.

Infant formula must be the sole source of nutrients for several months during a critical phase of growth 